\title{
Levels and Distribution of Pesticide Residues in Water and Soil from the Hydromorphic Rice Valleys of Pemba Island - Zanzibar, Tanzania
}

\author{
Haji Mwevura*, Hassan Said Hassan \\ Department of Natural Sciences, State University of Zanzibar, P O Box 146, Zanzibar, Tanzania. \\ *Corresponding Author: Haji Mwevura, Department of Natural Sciences, State University of Zanzibar, \\ P O Box 146, Zanzibar, Tanzania.
}

\begin{abstract}
This study reports the status of pesticide pollution associated with rice farming in the hydromorphic valleys in Pemba. Analysis of surface waters, ground waters and soil revealed presence of ten types of pesticide residues belong to organochlorine pesticides (OCPs), organophosphate pesticides (OPPs) and herbicides. The residue composition indicated fingerprints of past use of OCPs coupled with current use OPPs and herbicides. There were no significant variations among the valleys but clear distinction of current use of OPPs in valleys under community management from past of OCPs in government managed valleys. The valleys showed significant variations of OPPs levels between the sampling periods while OCPs were quite stable with the exception HCHs. The spatial distribution was largely influenced by use pattern under existing governance of the valleys whereas temporal variations reflect the low persistence of OPPS and herbicides in tropical environment. Although the measured levels were in a lower side of the related studies but detection of OPPs in groundwater in some valleys call for the establishment of management and monitoring plans that will oversee use of pesticides in these valleys to safeguard the health of these fragile ecosystems.
\end{abstract}

Keywords: Hydromorphic valley, Pemba, Organophosphate, herbicides, rice farming

\section{INTRODUCTION}

Pemba Island which is part of Zanzibar in the United Republic of Tanzania, is situated between latitude of $34^{\circ} 1^{\prime} 0^{\prime \prime} \mathrm{N}$ and $5^{\circ} 14^{\prime} 32^{\prime \prime} \mathrm{S}$, and longitude of $118^{\circ} 8^{\prime} 0^{\prime \prime}$ and $39^{\circ} 48^{\prime} 7^{\prime \prime} \mathrm{E}$. It has a population of 432,100 people of which $70 \%$ depends on agricultural activities as their main livelihood option (NBS, 2012). The island is partly undulating with many crevices and valleys and about $30 \%$ of the land is not suitable for agriculture activities as it is covered by coral rag soil, especially along east coast. Agriculture in Pemba is characterised by a wide variety of intricate mixed cropping systems dominated by rice growing activities. The rice farming activities are carried out within hydromorphic valleys located along western and southern part of the island. The suitability of the hydromorphic valleys for rice farming is attributed by high soil fertility and presence of permanent and temporary running streams assisted by very shallow water table.

Rice is the most preferred food in Zanzibar and its annual demand is estimated between 90,000 to 120,000 tons(MALNR, 2017). The major policy of rice farming in Zanzibar has been self-sufficiency in rice and a number of initiatives have been taken by the Zanzibar Government to increase the production. Despite subsidies such as provision of tractor services, rice development projects, irrigation schemes and other input into the sector, rice production is far below the demand. The production is estimated to provide $20 \%$ of the total demand (MALNR, 2017). Declining yields and Population growth make it extremely difficult to even maintain the production levels and therefore self sufficient in rice production has become flying target.

The decline in rice production is attributed by number of factors including small scale farming that uses low technology and frequent pest outbreak. The pest problems in Pemba are typical to sub-humid tropical agriculture and oftenly observed in every season. Consequently pesticides are routinely used to reduce possible losses due to pest and the intensity of pesticide use increase during the pest outbreak period.Common pests that have been reported to affect rice farming are rice hispa beetle 
(Trischispasericea), rice yellow mottle virus, stem borer (Chilopartellusspp). Others are rice blast (Pyriculariaoryzae), army worm (Spodopteraexempta)(Mmochi and Mberek, 1998; Stadlinger et al, 2013).

Currently, the amount of imported pesticides is not exactly known but it is estimated to be not more than 10 tonnes per annum(Ali, 2010). The significant portion of these pesticides (70\%) is used in rice fields while use in other crops is very minimal. Types of imported pesticides have changed from organochlorine to organophosphates, carbamates and pyrethroids. Organochlorine pesticides (DDTs, HCHs and cyclodienes) were banned because of their high persistence and replaced with environmental friendly groups of pesticides (organophosphorous, carbamates and pyrethroids) that are less persistent(Ali, 2010; Stadlinger, 2013). Despite being considered as environmentally friendly, these less persistent pesticides are more toxic with higher knocking down effect than the previously used organochlorine. Thus, the change in types has resulted to release of chemicals with higher acute toxicity index (Mmochi and Mberek, 1998) which is more harmful to untargeted organisms and pesticide users. This situation is acerbated low levels of farmers' knowledge on pesticides (Stadlingeret al, 2011; Silva et al., 2017). While the previously used pesticides were insoluble in water but capable of bio accumulating in the organism tissues, the currently used pesticides are relatively more soluble (Tomlin, 2000) making them potential groundwater contaminants.

Pesticides are extensively used in hydromorphic rice valleys in Pemba during pest out break and during weeding. Considering the characteristics of hydromorphic valleys such use of pesticides may eventually contaminate the groundwater and the contamination is more aggravated by solubility nature of the used chemicals. Despite the sensitive nature of the valleys, little is known on the distribution and fate of these pesticides in the environment. The present study was therefore conducted to assess status of pesticide pollution, their spatial and temporal variations in the rice hydromorphic valleys in Pemba.

\section{MATERIALS AND METHODS}

\subsection{Study areas and Samples}

The study areas receive the total average rainfall of $1500 \mathrm{~mm}$ per annum, half of which fall during long rain between March and May. The valleys are characterised by very high water table and are also associated with running streams pass through rice farms. These features make the areas most favourable for rice growing. All valleys have dugout wells or permanent wells acting as a source of potable water for farmers and even nearby communities.

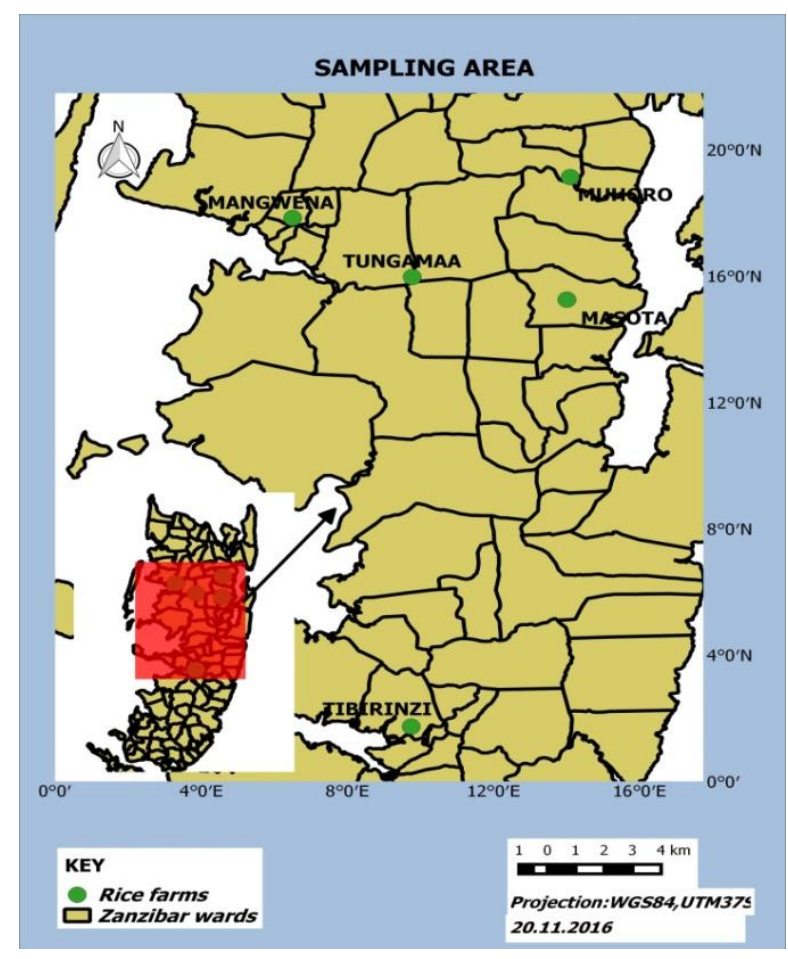

Figure 1. The map of Pemba Island in Zanzibar showing sampling locations 
Levels and Distribution of Pesticide Residues in Water and Soil from the Hydromorphic Rice Valleys of Pemba Island - Zanzibar, Tanzania

A total of 58 samples composed of 9 surface waters, 9 groundwater and 40 soil samples were collected in rice farms from five hydromophic valleys including Muhoro, Mangwena, Masota Tibirinziand Tungamaa. The samples were collected twice; during application time following the pest outbreak in 2016 and after harvesting. The sampling sites were marked using GPS and the locations are presented in Figure 1.Muhoro and Mangwena valleys are under community management while others (Masota, Tibirinzi and Tungamaa) are within the irrigation scheme under the control of the Ministry of Agriculture but allocated to farmers on seasonal basis.

\subsection{Sample Processing and analysis}

One litre of unfiltered water was liquid-liquid extracted successively by $120,60,60 \mathrm{ml}$ of dichloromethane and soil samples were extracted by a Solid Dispersion Extraction (SDE) method using acetone: cyclohexane $(1: 1)$ as described by Åkerblom(1995). The extracts were filtering through anhydrous sodium sulphate and cleaned up by manual GPC; however, portions of some of the extracts were also cleaned by sulphuric acid treatment. The cleaned extracts were then concentrated using a rotary evaporator and the solvent exchanged into cyclohexane acetone $(9: 1)$ for analysis.

The analysis was performed using Gas Chromatography-Mass Spectrometry GCMS-2010 Shimadzu instrument operating in EI mode (MS) at 70ev, and ECD detector for GC. The injection temperature was $250^{\circ} \mathrm{C}$ with splitless injection mode. A Restek-5MS column $(30 \mathrm{~m} \times 0.25 \mathrm{~mm} \times 0.25 \mu \mathrm{m})$ was used. The oven temperature program was $90^{\circ} \mathrm{C}$ to $280^{\circ} \mathrm{C}$ but held at $90^{\circ} \mathrm{C}$ for two minutes before being raised at a rate $6^{\circ} \mathrm{C}$ per minute. Helium was used as carrier gas at a flow rate of $1.21 \mathrm{ml} \mathrm{min}^{-1}$. The ion source temperature and interface temperature in MS were $230^{\circ} \mathrm{C}$ and $300^{\circ} \mathrm{C}$, respectively.

\section{RESULTS AND DISCUSSION}

The analysis revealed presence of nine individual pesticides residues belong to organochlorine pesticides (OCPs), organophosphate pesticides (OPPs) and herbicides. The detection frequencies and ranges of individual measured pesticides in surface water, ground water and soil are presented in Table 1, 2 and 3 respectively.

Table1. detection frequency and range of the measured pesticides in surface water

\begin{tabular}{|c|c|c|c|c|c|c|}
\hline \multirow{2}{*}{$\begin{array}{l}\text { Pesticide } \\
\text { Class }\end{array}$} & \multirow[t]{2}{*}{ Group } & \multirow[t]{2}{*}{ Pesticide } & \multicolumn{2}{|c|}{ Application } & \multicolumn{2}{|c|}{ Harvesting } \\
\hline & & & $\begin{array}{l}\text { Detection } \\
\text { freq. }(\%)\end{array}$ & $\begin{array}{c}\text { Conc. range } \\
(\mu \mathrm{g} / \mathrm{l})\end{array}$ & $\begin{array}{l}\text { Detection } \\
\text { freq }(\%)\end{array}$ & $\begin{array}{l}\text { Conc. } \\
(\mu \mathrm{g} / \mathrm{l})\end{array}$ \\
\hline \multirow[t]{5}{*}{ OCPs } & \multirow[t]{2}{*}{ DDTs } & pp-DDE & 44 & ND-1.6 & 33 & ND-0.72 \\
\hline & & pp-DDD & 11 & ND-0.17 & 11 & ND - 0.12 \\
\hline & \multirow[t]{2}{*}{$\mathrm{HCH}$} & $\alpha-\mathrm{HCH}$ & 33 & ND-0.74 & 22 & ND-0.3 \\
\hline & & $\gamma-\mathrm{HCH}$ & 44 & ND-1.7 & 22 & ND-0.8 \\
\hline & Cyclodiene & dieldrin & 11 & ND-1.3 & 0 & ND \\
\hline \multirow[t]{3}{*}{ OPPs } & \multicolumn{2}{|c|}{ Fenitrothion } & 66 & ND-2.50 & 0 & ND \\
\hline & \multicolumn{2}{|c|}{ Diazinon } & 33 & ND-2.32 & 0 & ND \\
\hline & \multicolumn{2}{|c|}{ Chloropyrifos } & 33 & ND-1.8 & 0 & ND \\
\hline \multirow[t]{2}{*}{ Herbicides } & \multicolumn{2}{|c|}{ Propanil } & 66 & ND-3.25 & 0 & ND \\
\hline & \multicolumn{2}{|c|}{ Thiobencarb } & 44 & ND-5.1 & 0 & ND \\
\hline
\end{tabular}

Table2. detection frequency and range of the measured pesticides in groundwater

\begin{tabular}{|l|c|c|c|}
\hline Class & \multicolumn{2}{|l|}{ Pesticide } & \multicolumn{2}{|c|}{ Application } \\
\cline { 2 - 4 } & & Detection $(\boldsymbol{\%})$ & Conc. $(\boldsymbol{\mu g} / \mathbf{l})$ \\
\hline \multirow{3}{*}{ OPPs } & Fenitrothion & $11 \%$ & ND-0.36 \\
\cline { 2 - 4 } & Diazinon & $11 \%$ & ND-0.42 \\
\cline { 2 - 4 } & Chloropyrifos & $11 \%$ & ND-0.2 \\
\hline \multirow{2}{*}{ Herbicides } & Propanil & $11 \%$ & ND-0.1 \\
\cline { 2 - 4 } & Thiobencarb & $22 \%$ & ND-1.1 \\
\cline { 2 - 4 } & &
\end{tabular}

Note: No pesticides was detected in ground water during harvesting 
Levels and Distribution of Pesticide Residues in Water and Soil from the Hydromorphic Rice Valleys of Pemba Island - Zanzibar, Tanzania

Table3. detection frequency and range of the measured pesticides in soil

\begin{tabular}{|c|c|c|c|c|c|c|}
\hline \multirow[t]{2}{*}{ Class } & \multirow[t]{2}{*}{ Group } & \multirow[t]{2}{*}{ pesticide } & \multicolumn{2}{|c|}{ Application } & \multicolumn{2}{|c|}{ Harvesting } \\
\hline & & & $\begin{array}{l}\text { Detection freq } \\
(\%)\end{array}$ & $\begin{array}{l}\text { Conc } \\
(\mathrm{ng} / \mathrm{g})\end{array}$ & $\begin{array}{l}\text { Detection } \\
\text { freq }(\%)\end{array}$ & $\begin{array}{l}\text { Conc } \\
(\mathrm{ng} / \mathrm{g})\end{array}$ \\
\hline \multirow[t]{5}{*}{ OCPs } & \multirow[t]{2}{*}{ DDTs } & pp-DDE & 85 & 0.23-3.08 & 55 & 0.06-2.15 \\
\hline & & pp-DDD & 40 & ND-0.49 & 20 & ND-0.21 \\
\hline & \multirow[t]{2}{*}{$\mathrm{HCH}$} & $\alpha-\mathrm{HCH}$ & 25 & ND-0.16 & 15 & ND-0.07 \\
\hline & & $\gamma-\mathrm{HCH}$ & 70 & $0.5-2.12$ & 40 & ND-0.32 \\
\hline & Cyclodiene & dieldrin & 5 & ND-0.75 & 5 & ND-0.35 \\
\hline \multirow[t]{2}{*}{ OPPs } & \multicolumn{2}{|c|}{ Fenitrothion } & 75 & $1.05-1.74$ & 0 & $\mathrm{ND}$ \\
\hline & \multicolumn{2}{|c|}{ Diazinon } & 70 & $0.98-1.45$ & 0 & ND \\
\hline
\end{tabular}

\subsection{Residues of Organochlorine Pesticides (OCPs)}

The OCPs detected in this study composed of HCHs, DDTs and cyclodienes groups. There were no significant differences of their both detection frequencies and concentrations in surface water and soil throughout the study period. However the concentrations of p,p'-DDE and $\gamma-\mathrm{HCH}$ were slightly higher compared to other OCPs. On the other hand, all OCPs were below detection in ground water. In surface water concentrations of OCPs were measured at mean values of $1.85 \mu \mathrm{g} / \mathrm{l}(\mathrm{ND}-5.51 \mu \mathrm{g} / \mathrm{l})$

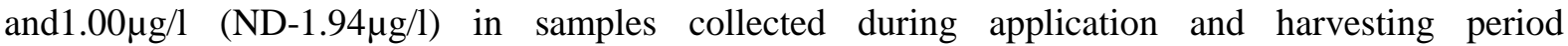
respectively. During application period the total OCPs (HCHs + DDTs + cyclodienes) in soil ranged from 0.38 to $6.56 \mathrm{ng} / \mathrm{g}$ (Mean 3.25ng/g) while the range of the OCPs during harvesting was 0.06 $4.49 \mathrm{ng} / \mathrm{g}$ (Mean1.38ng/g).

\subsection{Hexachlorohexanes (CHs)}

Only two isomers of $\mathrm{HCHs}(\alpha-\mathrm{HCH}$ and $\gamma-\mathrm{HCH})$ were detected in the analysed samples. The total $\mathrm{HCH}(\alpha-\mathrm{HCH}+\gamma-\mathrm{HCH})$ in water ranged from ND-2.44 $\mu \mathrm{g} / \mathrm{l}$ during application and ND $-1.10 \mu \mathrm{g} / \mathrm{l}$ during harvesting; whereas in soil the ranges were $0.1-2.24 \mathrm{ng} / \mathrm{g}$ and ND $-0.34 \mathrm{ng} / \mathrm{g}$ in application and harvesting periods, respectively. During application period, $\gamma-\mathrm{HCH}$ isomer (lindane) was measured in relatively higher frequencies in water $(44 \%)$ and soil $(70 \%)$ than the $\alpha-\mathrm{HCH}$ isomer which was detected in $33 \%$ in water and $25 \%$ in soil samples. Similarly during harvesting, $\gamma-\mathrm{HCH}$ had higher detection frequency $(40 \%)$ than $\alpha-\mathrm{HCH}(15 \%)$ in soil but both isomers were measured in $22 \%$ of the water samples. The comparably lower detection frequencies of $\alpha-\mathrm{HCH}$ isomer in all matrices compared to $\gamma-\mathrm{HCH}$ isomer is an indication of past use of technical $\mathrm{HCH}$ mixtures coupled with current use of lindane.

This use trend is also confirmed by contribution of $\alpha-\mathrm{HCH}$ and $\gamma-\mathrm{HCH}$ in the total $\mathrm{HCH}$ measure in the matrices. The ratio of $\alpha-\mathrm{HCH} / \gamma-\mathrm{HCH}$ has been used to investigate whether the $\mathrm{HCH}$ found its way to environment as technical product or pure lindane. The technical $\mathrm{HCH}$ formulation is dominated by the $\alpha$-isomers (60\%-70\%) while the insecticidal active $\gamma$-isomer comprises only (10-15\%) of the technical product and the other two isomers $\beta$ and $\delta$ are (5-12\%) and (6-10\%), respectively (Wang et al., 2006). On the other hand, lindane formulation is normally composed of only $\gamma-\mathrm{HCH}$ isomer (99\%) (Tomlin, 2000). The ratio $\alpha-\mathrm{HCH}: \gamma-\mathrm{HCH}$ associated with the use of fresh technical $\mathrm{HCH}$ is expected to range from 4-7, and the ratios below four but greater than zero $(4>$ ratio $>0)$ indicate that $\gamma-$ $\mathrm{HCH}$ was also in use in that particular location(Zhang et al, 2004). Since $\gamma$-HCH dissipate at faster rate than $\alpha-\mathrm{HCH}$, for aged technical mixtures the ratios in the environment can be above seven and the ratio is zero if technical $\mathrm{HCH}$ has not been used at all (Wang et al., 2006). In this study the $\alpha-\mathrm{HCH} / \gamma$ $\mathrm{HCH}$ ratios in during both application and harvesting period ranged between 0.5 to 1.63 and 0.06 to 0.12 in water and soil samples, respectively. These ratios indicate predominance of current use of $\gamma$ $\mathrm{HCH}$ instead of technical mixtures in the hydromorphic rice valleys (Padma and Dickhurt, 2002).

The finding is also complying with the reporteduse-shift from technical mixture which contains small proportion of pesticidal chemical $(\gamma-\mathrm{HCH})$ to lindane which contains more than $90 \%$ of $\gamma-\mathrm{HCH}$ (Ali, 2010). Decrease in concentration of $\gamma-\mathrm{HCH}$ during harvesting period indicates that the isomer has significantly degraded between the application to harvesting (Mwevura, 2008). 


\subsection{DDTs}

For the case of DDTs, only two metabolites namely p,p'-DDE and p,p.-DDD were detected and the parent molecules (p,p'-DDT and p,p'-DDT) were below detectionin all samples. The degradation metabolites p,p'-DDE predominated the other metabolite in all matrices. The ranges of total DDT (p,p'-DDE + p,p'-DDD) concentrations within the valleys were ND-1.77 $\mu \mathrm{g} / \mathrm{l}$ in water and 0.26 $3.57 \mathrm{ng} / \mathrm{g}$ in soil during application. The concentration ranges were alsoND-0.84 $\mu \mathrm{g} / 1$ in water and0.06 - 3.80ng/gin soil during harvesting period.

It is known that, DDT is always released into the environment as technical mixture consisting of parent molecules p,p'-DDT (90\%) and o,p'-DDT (10\%) of which o,p'-DDT is less stable. Once released, it can be reductively dechlorinated to DDD and dehydrochlorinated to DDE metabolites which are more stable and persistent than their parent molecules (Wang et al., 2006). Detection of DDT degradation products with the absence of parent molecules of DDT is a clear indication of past use of these OCPs.

The ratios of metabolites/parent compound (DDE+DDD/SDDT) which give the fraction of degradation metabolites in total DDT have been used to assess age of the pesticide in the environment. Generally, a value of $(\mathrm{DDE}+\mathrm{DDD}) / \Sigma \mathrm{DDT}$ ratio $>0.5$ indicate past use of DDT and recent use is indicated by the ratio $<0.5$ (Wang et al., 2006). In the present study total DDT measured in both water and soil matrices was entirely contributed by metabolites and no parent molecule was found in both water and soil samples. This make ratio of metabolites to parent molecule equal to one which is equivalent to $100 \%$ contribution of metabolites. These findings give evidence of the very past use of DDT within the hydromorphic rice valleys in Pemba Island.

Comparisons of the two identified metabolites in soil can assist to understand the degradation pathway of DDT in soil and thus assessing dominating degradation process of the fresh DDT in the hydromorphic valleys. If the DDD to DDE ratio $>1$ indicates the particular environment favors anaerobic degradation and if the value is $<1$ the environment favors aerobic degradation (Yao et al., 2006). In this study the ratios of DDD/DDE were less than one during both application and harvesting periods implying that the hydromorphic rice valleys favor aerobic degradation of DDT.

\subsection{Cyclodienes}

Dieldrin, was the only cyclodiene detected in this study. It was detected in water during application period, and in soil during both application and harvesting periods. Water collected during harvesting period had no detectable levels of cylodines. The cyclodine was measured at Tibirinzi rice valley only and not in any other rice valley. Its peculiar detection at Tibirinzi rice valley only might be attributed by municipal run-off as the valley is located downstream the Chake-Chake town and part of municipal wastewater end-up within the valley.

In general, the findings of this study indicate that the presence of OCPs (HCHs+DDTs+cyclodienes) is a result of past use of the chemicals. These compounds are among the substances that were restricted or banned globally under the Stockholm convention on Persistent Organic Pollutants (POPs) in 1997 (Kishimba et al., 2004) and their use was also banned in Tanzania in 1997 (Mmochi, 2005).It is worth noting that all OCPs detected in water matrix were from surface water and no single ground water sample had detectable residues of OCPs. Groundwater samples were very clear compared to surface water samples which had suspended particles. Presence of OCPs in surface water was likely attributed by suspended particles which sorbed OCPs as samples were extracted without being filtered. This observation is in agreement with high hydrophobic nature of OCPs which make them preferentiallysorbed to sediment or soil particles in aquatic system (Imo et al., 2013; Golfinopoulos et al., 2003; Mwevura et al 2002).

\subsection{Residues of OPPsand Herbicides}

Three pesticides namely;fenitrothion, diazinon and chloropyrifos from the OPPsgroup were detected in all matrices collected during application. Among them, fenitrothion showed highest detection frequencies in both water and soil. The total OPPs (fenitrothion + diazinon + chloropyrifos) concentrationsin application period ranged fromND- 6.62 $\mu \mathrm{g} / \mathrm{lin}$ water and $2.65-4.45 \mathrm{ng} / \mathrm{g}$ in soil. Their average values were $2.10 \mu \mathrm{g} / \mathrm{l}$ and $3.34 \mathrm{ng} / \mathrm{gin}$ water and soil, respectively. 
In the same application period, herbicides (propanil and thiobencarb) were detected in both water and soil matrices from Muhoro and Masota valleys. The herbicides were below detection in samples from other valleys. Propanil was recorded at relatively higher frequencies than thiobencarb in both water and soil matrices. The total herbicide concentrations (propanil + thiobencarb) were up to $7.36 \mu \mathrm{g} / \mathrm{land}$ $5.03 \mathrm{ng} / \mathrm{g}$ in water and soil, respectively.

All OPPs and herbicides decreased significantly and their concentrations were below detection in all water and soil samples collected during harvesting. A notable higher detection frequency of OPP and herbicides during application than harvesting is a clear indication of current use in OPPsthe valleys. Contrary to OCPs, the OPPs and herbicides residues were found in all surface water samples and one ground water sample during application period. The contaminated ground water sample was from Muhoro rice valley and it had residues of all measured OPPs and herbicides.

Relative Higher detection frequencies of OPPs compared to OCPs in water were probably attributed by low hydrophobic nature of OPPs compared to OCPs (Añascoet al., 2010). Most OPPs are relatively water-soluble; making them more likely to be dissolved during heavy rains, which coincides with application period. Moreover, processes like hydrolysis, photolysis, microbial degradation and evaporation are likely to contribute to the decline of OPPs in soil (Lalah et al., 2001). These phenomena account for OPPs and herbicides disappearance between the sampling periods and thus confirm their relative instability in the environment. The pesticides have very low half life and are not expected to bio accumulate in soil and sediments for long time (Tomlin, 2000).

\subsection{Spatial and Temporal variations of residues in valleys}

Assessment of spatial variations within the sites was accomplished by comparing total residue load (total OCPs + total OPPs + total Herbicides) in both matrices. The two matrices give different contamination trends when they are treated separately. With respect to residue load in water, the contamination trend is Muhoro>Masota>Tibirinzi>Tungamaa>Mangwena (Figure 2) whereas with respect to residue load in soil the observed trend is Tibirinzi>Muhoro>Mangwena>Tungamaa $>$ Masota (Figure 3).

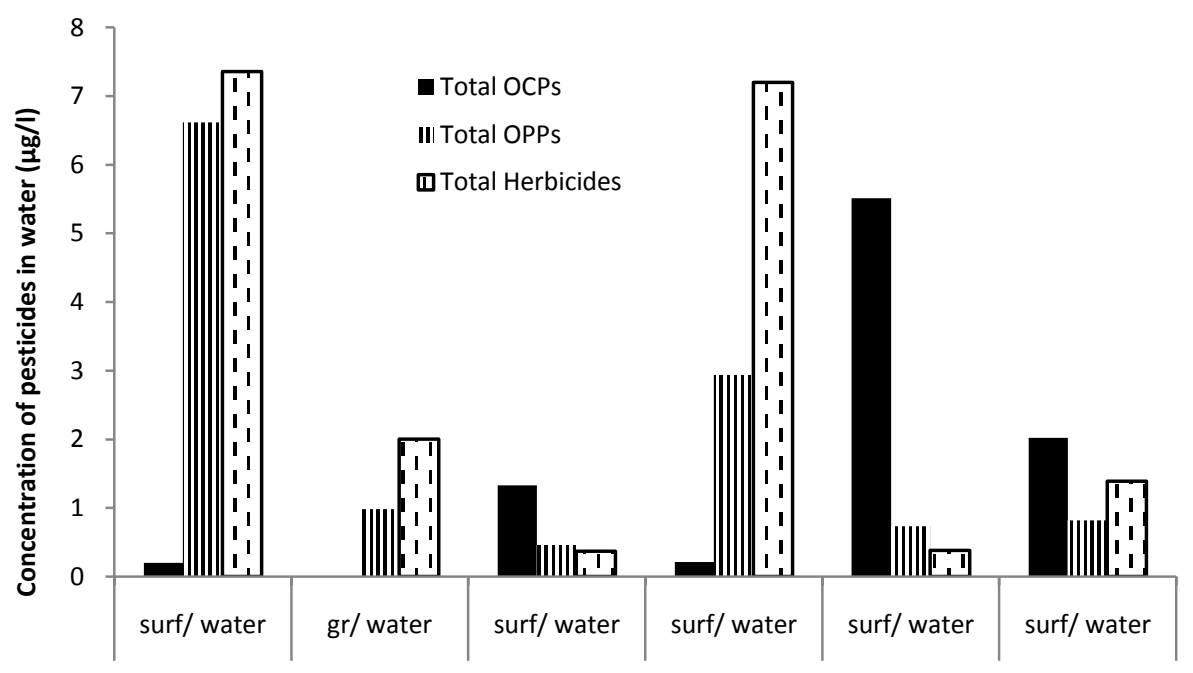

Figure 2. Spatial Variations of Pesticide Residues in Water 


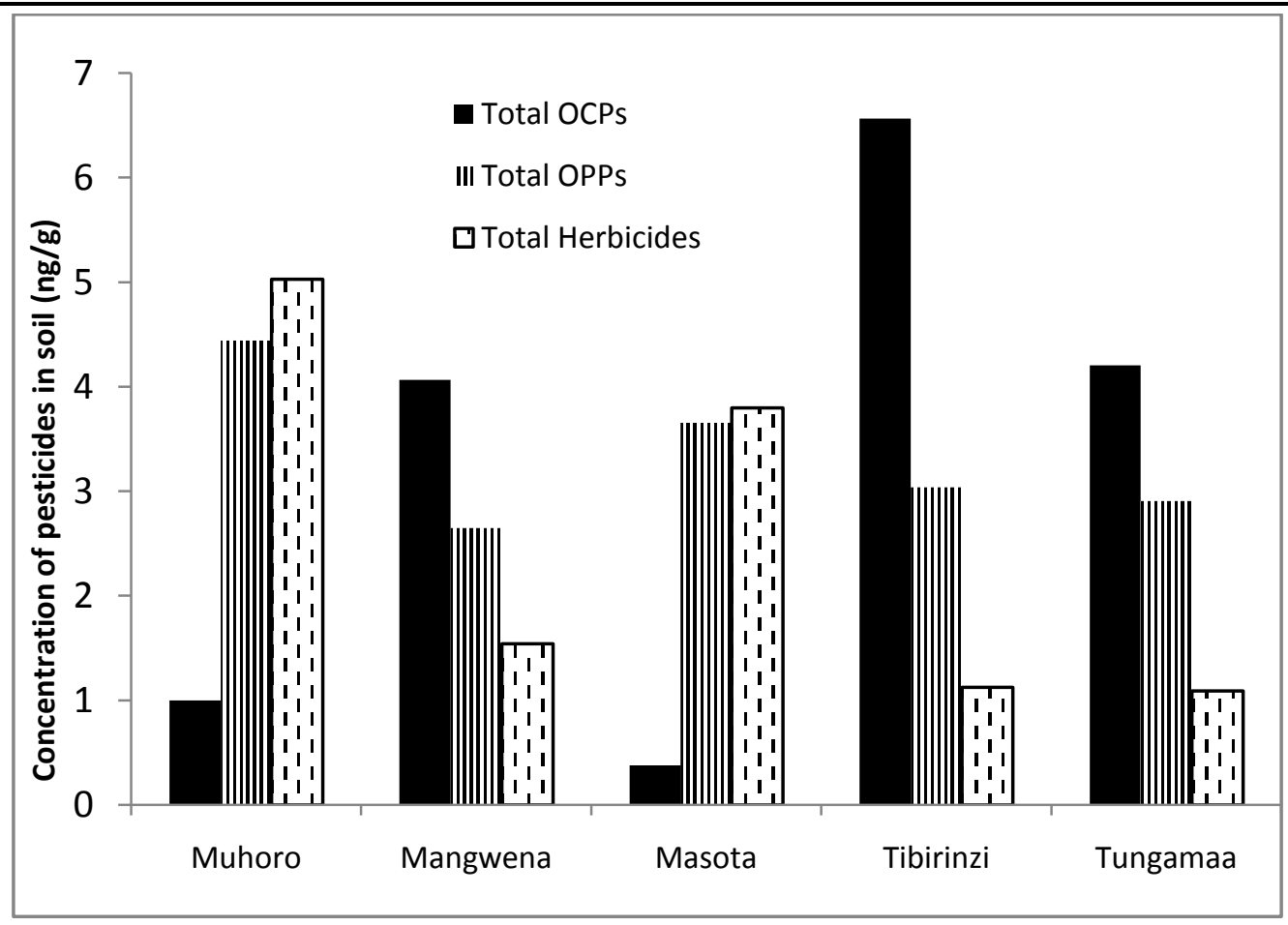

Figure 3. Spatial Variations of Pesticide Residues in Soil

These observed trends of spatial variations based on matrix were largely governed by the hydrophobic and water solubility properties of the used pesticides. The OPPs and herbicides are more watersoluble (Eamkamon et al., 2012) and thus influencing water based trend; and OCPs on the other hand influenced soil based trend as they are hydrophobic and likely to be adsorbed in soil matrices (Galhano et al., 2011). Residues load at Muhoro valley was largely contributed by OPPs which were measured at reasonable amount in water within the valley while pollution in Tibirinzi valley load was contributed by OCPs which are characterized with high hydrophobicity and that portioned to organic part of the soil.

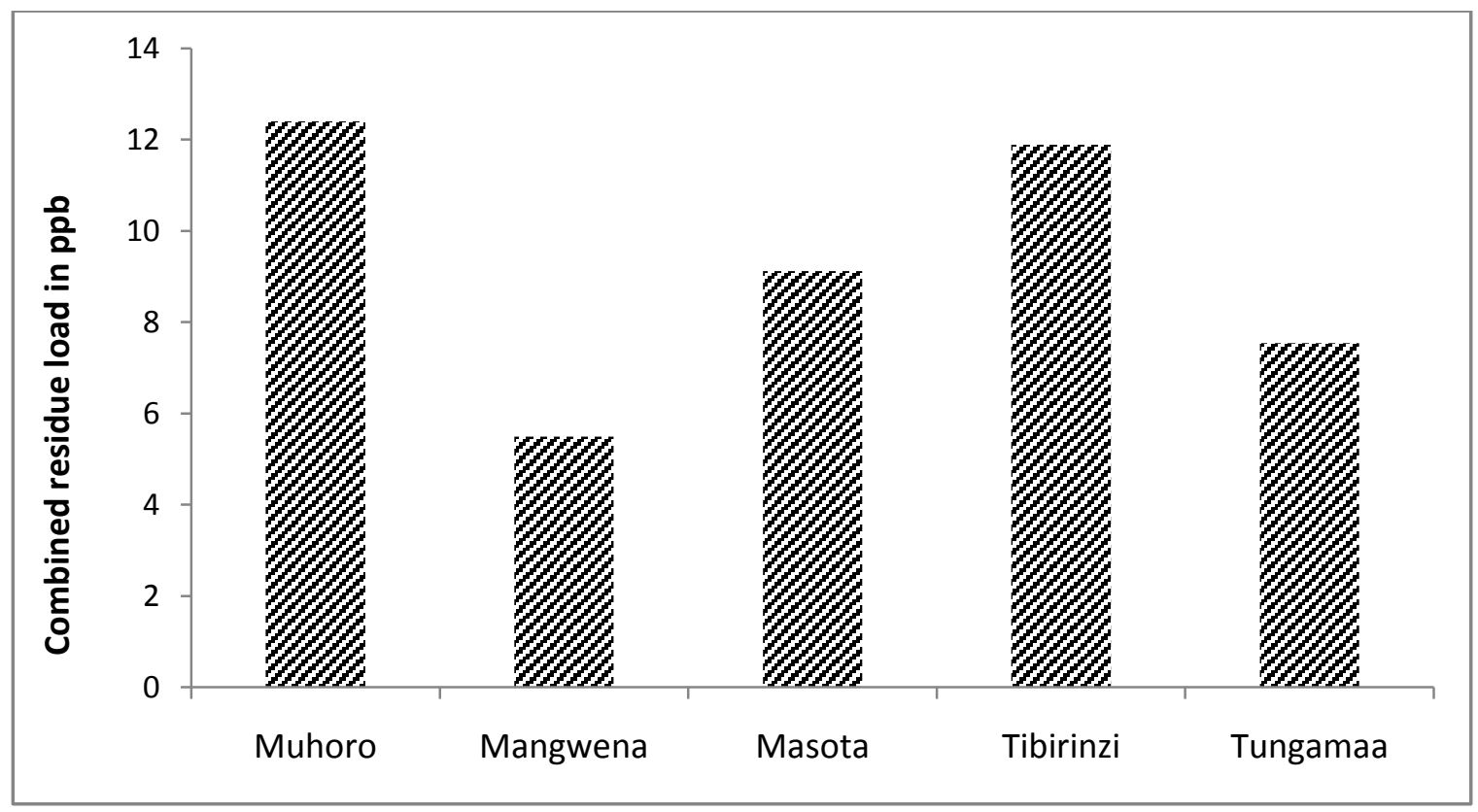

Figure 4. Spatial Variations of Total combined load of Pesticide Residues in valleys

Considering combined residue load from both water and soil in part per billion (ppb) (conc. in water $(\mu \mathrm{g} / \mathrm{l})+$ conc. in soil $(\mathrm{ng} / \mathrm{g}))$, the contamination trends also differed between the two sampling periods. During pesticide application period, the observed contamination trend was Muhoro>Masota>Tibirinzi>Tungamaa>Mangwena which is identical to that observed in water 
matrix. This trend seems to be largely influenced by OPPs and herbicides in water. During harvesting the only residues that were detected were OCPs and its combined residue load (Total OCPs in water + Total OCPs in soil) is Tibirinzi $>$ Tungamaa $>$ Mangwena $>$ Muhoro $>$ Masota. This trend is different from that depicted by soil indicating that water samples also contributed to levels of OCP. The OCPs in water waslikely associated with suspended particles. However, the combined spatial variation trend of the residue load irrespective of the sampling season was Muhoro $>$ Tibirinzi $>$ Masota $>$ Tungamaa $>$ Mangwena(Figure 4)

Hydromorphic valleys under study are in two systems of management. Tibirinzi, Tungamaa and Mangwena valleys are under irrigation scheme and are managed by the Ministry of Agriculture but Muhoro and Masota valley are managed by surrounding community and not included in irrigation scheme. The spatial variations of residues load indicate that non-irrigated rice valleys are relatively polluted compared to those that are under irrigation scheme during application period and the opposite is true during harvesting. The major contributing factor on the observed combined trends is the uncontrolled use of OPPs and herbicides in community-governed valleys while use of pesticides is restricted within the valleys governed by the Ministry (Khamis, 2016, personal communication).

At application time the valleys showed two different trends of residues distribution. The trend is total herbicide >total OPPs >OCPs, which is depicted by Muhoro and Masota valley while the other trend depicts dominance OCPs (total OCPs $>$ total OPPs $>$ total herbicide or total OCPs $>$ total herbicide $>$ total OPPs) within Tibirinzi, Tungamaa and Mangwena valleys. The two trends reflect influence governance system among the valleys. Muhoro and Masota are predominated by currently used pesticides (OPPs and Herbicides), while the levels of previously used OCPs are very low. According to irrigation scheme incharge in Pemba, it is strictly prohibited to use herbicide within the irrigation scheme but other pesticides can be used only if there is pest out break. However, despite of restriction kept by the ministry, it seems that herbicides are also finding their way to the irrigation scheme valleys.

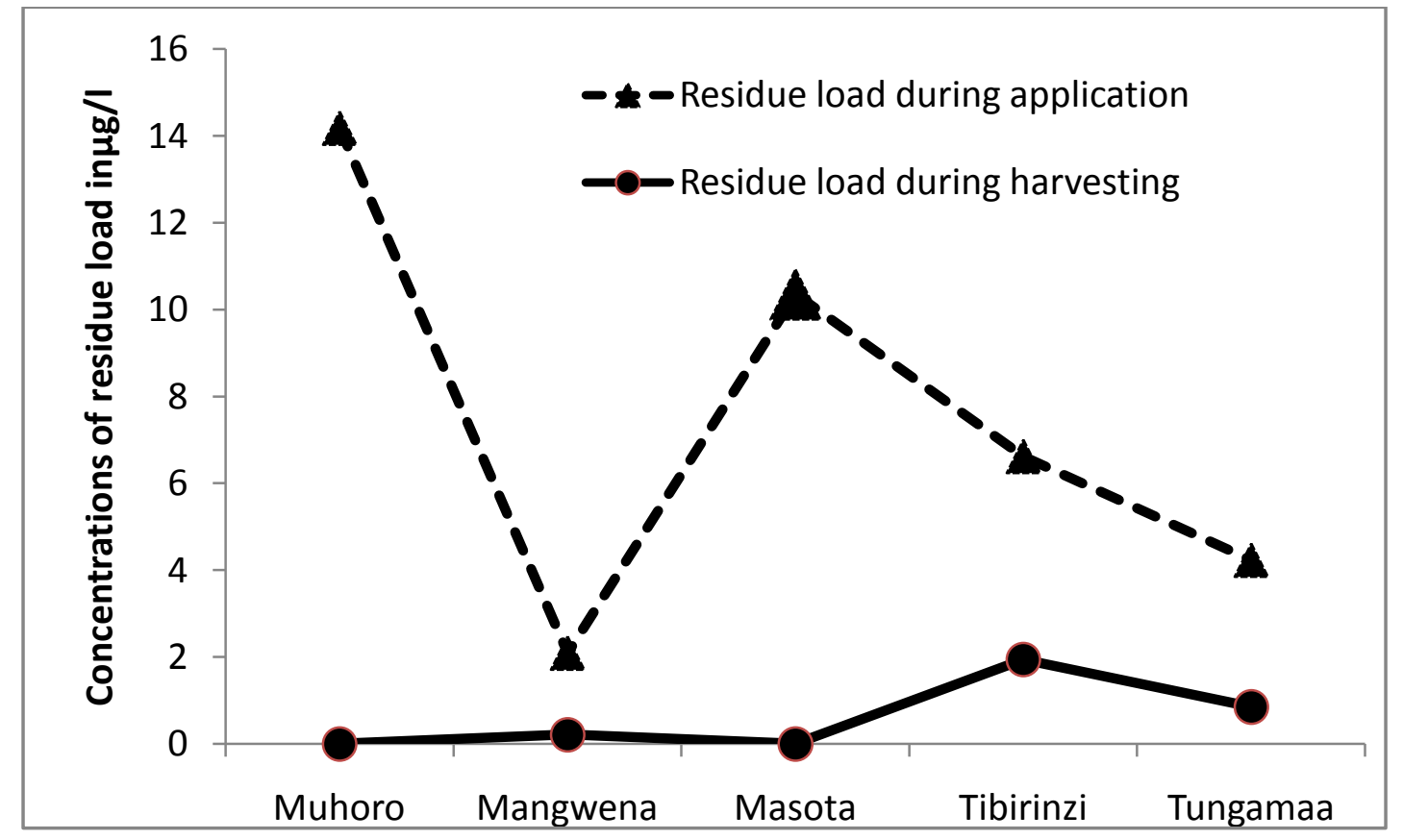

Figure 5. Temporal Variations of Total combined load of Pesticide Residues in valleys

Temporal variations of the residual load of pesticides in water and soil samples are presented in Figure 5. In general, there was decrease in residual load from application period to harvesting period. This temporal variations was obviously due to significant decrease of OPPs and herbicides coupled with very little variations of OCPs. Significant temporal variations were observed at Muhoro and Masota the valleys that are applied with OPPs while other valleys gave minor temporal variations. The OPPs and herbicides were heavily applied during application/weeding period followed by their significant dissipation to non-detectable level during harvesting. On the other hand OCPs are quite 
Levels and Distribution of Pesticide Residues in Water and Soil from the Hydromorphic Rice Valleys of Pemba Island - Zanzibar, Tanzania

stable and are seldomly dissipate and thus they showed no variations. OCPs were mainly measured in irrigated valleys and their presences are associate with their past use before the ban (PPS, 2016).

\section{Comparison with related Studies}

Several studies focusing on levels and behavior of pesticides in rice farms have been conducted worldwide. In general the present study resembles in terms of classes of identified pesticides and variations of residues with similar study conducted in Rufiji rice farms. However, the number of identified pesticides as well as their levels measured in this study are lower than those reported in water and soil from rice farms within Rufiji (Mwevura, 2008). Further comparisons with other related studies of pesticide residues in rice farms reveals that, this study detected few types of pesticides residues at lower concentrations compared to studies in other regions (Wang et al., 2006; Dos-Santos, 2008).

The differences in types and levels are probably reflecting to pattern and intensity of pesticide use. It is likely that large amount of pesticides used in those areas resulting to higher levels compared to amount detected in hydromorphic rice valleys in Pemba. This comparison reveals that Pemba hydromorphic rice valleys are relatively less polluted compared to other rice farms in Tanzania and other part of the world. Comparison of the levels of pesticides measured in ground water with different drinking water standards indicated that the levels were below many drinking water standards (EU, 1998; WHO, 2008). Although the contamination levels of ground has no immediate direct effect to consumer, however detection of the pesticides in groundwater is of more concern. Repetitive heavy application of pesticides during every pest outbreak is likely to degrade the quality of ground water and is likely pose human health risks to farmers who are regularly using the water during rice farming.

\section{CONCLuSiON}

The hydromorphic rice valleys in Pemba are contaminated with pesticides originated from combination of past use of OCPs and current use of lindane, OPPs and herbicides. Spatial distribution of residues revealed that rice valleys under government management and irrigation schemes are dominated by OCPs while OPPs and herbicides dominate the valleys under community management due to their current use in the area. In general, Muhoro was the most contaminated valley during application period but the situation changes during harvesting by Tibirinzi becoming most polluted. There was a significant temporal variation associated with remarkable decrease of concentrations of OPPS and herbicides to non-detectable level. Both spatial and temporal are governed by pesticide use pattern which is determined by management system in the valleys. Ground water from Muhoro valleys are contaminated with low levels of residues that are below drinking water standards however repetitive use of OPPS and current may likely deteriorate the water quality and hence potability.

\section{ACKNOWLEDGEMENT}

The author would like to sincerely thanks support provided by Department of Narural Sciences of the State University of Zanzibar and the African Network for Chemical Analysis of Pesticides and other pollutants (ANCAP). We also acknowledge the support of Mr. Nassor Othman Khamis from irrigation Department Ministry of Agriculture during field work.

\section{REFERENCES}

Åkerblom, M. Environmental Monitoring of Pesticide residues, Guideline for the SADC Region,

Ali, T.M, 2010. Life Cycle assessment of Pesticides used in Zanzibar. BSc Project report, State university of Zanzibar, Tanzania.

Añasco N, Uno S, Koyama J, Matsuoka T, Kuwahara N. 2010.Assessment of pesticide residues in freshwater areas affected by rice paddy effluents in Southern Japan.Environmental Monitoring and Assessment 160: 371-383.

Eamkamon, T., Klinbunga, S., Thirakhupt, K., Menasveta, P.,and Puanglarp, N. (2012).Acute Toxicity and Neurotoxicity of Chlorpyrifos in Black Tiger Shrimp, Penaeusmonodon.Environment Asia 5(1) 26-31.

EU, 1998. EU's drinking water standards. Council Directive 98/83/EC on the quality of water intented for human consumption. EU Brussels

Galhano, V., Gomes-Laranjol, V., Fernandez-Valiente, E., Videira, R., and Peixoto, F. (2011). Impact of Herbicides on Non-Target Organisms in Suitable Irrigated Rice Production aSystems: Centre for Research and Technology of Agro-Environment and Biological Sciences, University of Trảs-os-Montes. 
Levels and Distribution of Pesticide Residues in Water and Soil from the Hydromorphic Rice Valleys of Pemba Island - Zanzibar, Tanzania

Golfinopoulos, S. K., Nikolaou, A.D., Kostopoulou, M.N., Xilourgidis, N.K., Vagi, M.C. and Lekkas, 2003 Organochlorine Pesticides in the Surface Waters of North Greece, Chemosphere 50, 507 - 516.

Imo, T.S., Oomari, T., Sheikh, M.A., Miyagi, T., and Tamaki, F. 2013.Spatial and Monthly Behaviuor of Selective Organochlorine Pesticides in Subtropical Estuarine Ecosystem.15: 428-443.

Khamis, N. O. 2017 Department of irrigation, Ministry of Agriculture, Fishery and Natural resources. Personal communication.

Kishimba, M.A., Henry, L., Mwevura, H., Mmochi, A.J., Mihale, M and Heller, H. 2004. The Status of Pesticide Pollution in Tanzania, Talanta, 64: 48 -53.

Lalah, J. O, Kaigwara, P. N., Getenga, Z, Mghenyi, J. M andWandiga, S. O (2001). The major environmental factors that influence rapid disappearance of pesticides from tropical soils in Kenya. J. Toxicol. Environ. Chem, Vol.81, 161-197.

Ministry of Agriculture, Livestock and Natural Resources (MALE), Zanzibar Food Security Report 2017.

Mmochi A.J. and Mberek, R.S. 1998. Trends in the types, amount and toxicity of pesticides used in Tanzania Efforts to control pesticide pollution in Zanzibar, Tanzania.Ambio 27, 669 - 676.

Mmochi, A.J. 2005. Levels and Chemodynamics of Pesticide Residues and Metabolites in the Zanzibar Coastal Marine Environment, PhD Thesis, University of Dar es salaam, Tanzania.

Mwevura, H. 2008. Chemodynamics of Pesticide Residues and Other Persistent Organic Pollutants Within Rufiji Delta and Dolphins from Coastal Waters of Zanzibar.Ph.D thesis University of Dar es Salaam, Tanzania

Mwevura, H., Othman, O.C. and Mhehe, G.L. (2002) Organochlorine pesticide residues in sediments and biota from the coastal area of Dar es Salaam city, Tanzania, Mar. Pollut. Bull. 45: 262 - 267

NBS, 2012. Population and housing census counts. Tanzania National Bureau of Statistics Website. http://www.nbs. go.tz/. Accessed October 20, 2017.

Padma, T. V. and Dickhut, R.M. 2002. Spatial and temporal variation in hexachlorocyclohexane isomers in temperate estuary.Marine pollution Bulletin 44: 1345 - 1353.

SADC ELMS Monitoring Technique Series, Sweden, 1995.

Silva, M., Stadlinger, N., Mmochi, A. J., Lundborg, C. S. and Marron G. 2016. Pesticide Use and Self-Reported Health Symptoms Among Rice Farmers in Zanzibar. Journal of Agromedicine, 21: 335-344

Stadlinger, N., Mmochi, A. J and Kumlad L. 2011. Pesticide use Among Smallholder Farmers in Tanzania. Environ. Dev. Sustain. 13: 641 - 656.

Stadlinger, N., Mmochi, A. J and Kumlad L. 2013. Weak Gorvenment Institutions Impair the Management of Pesticides importation and sales in Zanzibar. Ambio 42: 72 - 82.

Stadlinger, N.,2013 Pesticide IN Coastal Tanzania: Management, Policy and Concern for Health and the Environment. Ph.D thesis University of Stockholm, Sweden.

Tomlin, C.D.S (Ed) A World Compendium: The Pesticide Manual, 12 ${ }^{\text {th }}$ Edition, British Crop Protection Council, Surrey, UK, 2000.

Wang, F., Xin, J., Yong-rong, B., Fen-xia, Y., Hong-jian, G., Gui-fen, Y., Munch J., and Schroll, R., 2006. Organochlorine pesticides in soils under different land usage in the Taihu Lake region, China.Journal of Environmental Sciences 19 584-590.

WHO, 2008. Guidelines for drinking-water quality, $3^{\text {rd }}$ edition, WHO Geneva

Yao, F. X., Jiang, X., Yu, G. F. et al. (2006). Evaluation of accelerated dechlorination of p,p' -DDT in acidic paddy soil. Chemosphere, 64: 628-633.

Zhang Z, Huang J, Yu G, Hong H. 2004. Occurrence of PAHs, PCBs and organochlorine pesticides in the Tonghui River of Beijing, China. Environmental Pollution 130: 249-26.

Citation: H. Mwevura, H. S. Hassan, "Levels and Distribution of Pesticide Residues in Water and Soil from the Hydromorphic Rice Valleys of Pemba Island - Zanzibar, Tanzania ", International Journal of Research in Environmental Science, vol. 4, no. 1, p. 83-92, 2018. http://dx.doi.org/10.20431/2454-9444.0401011

Copyright: () 2018 Authors. This is an open-access article distributed under the terms of the Creative Commons Attribution License, which permits unrestricted use, distribution, and reproduction in any medium, provided the original author and source are credited. 